\title{
EFEITOS DE DIFERENTES TRATAMENTOS NA GERMINAÇÃO DO PEQUI (CARYOCAR BRASILIENSE CAMB.)
}

\author{
C. G. Sá e Carvalho' \\ R. A. Côrtes ${ }^{2}$ \\ I. F. Carneiro ${ }^{3}$ \\ J. D. Borges ${ }^{3}$
}

Recebido em 24.10.91. Aceito em 11.07.94.

\begin{abstract}
RESUMO - (Efeitos de diferentes tratamentos na germinação do pequi (Caryocar brasiliense Camb.)). Sementes de pequi (Caryocar brasiliense Camb.) provenientes de frutos coletados do chão e "de vez", foram submetidas aos seguintes tratamentos: choques térmicos úmido $\left(80^{\circ} \mathrm{C} / 15\right.$ $\min )$ e seco $\left(80^{\circ} \mathrm{C} / 15 \mathrm{~min}\right.$ e $50^{\circ} \mathrm{C} / 30,60,90$ e $\left.120 \mathrm{~min}\right)$, ácido giberélico $100 \mathrm{mg} / \mathrm{l}$ e 6 benzil aminopurina $10^{-4} \mathrm{M}$ durante 24 horas, ácido sulfúrico conc./ l hora e lavagem em água corrente/48 horas. Sementes provenientes de frutos coletados do chão, com parte do mesocarpo removido, e "de vez", com mesocarpo íntegro, foram armazenadas a $5^{\circ} \mathrm{C}$ durante 30 dias, seguido ou não pela adição de $\mathrm{GA}_{3} 100 \mathrm{mg} / \mathrm{l}$. Observou-se que a germinação do pequi começa consistentemente a partir do $9 .^{\circ}$ mês após o plantio não havendo diferença significativa entre a porcentagem de germinação de sementes provenientes de frutos colhidos "de vez" (85\%) e completamente maduros $(67 \%)$. Tratamentos das sementes com temperatura de $80^{\circ} \mathrm{C}$ durante $15 \mathrm{~min}$. com ácido sulfúrico concentrado durante 1 hora e estratificação a $5^{\circ} \mathrm{C}$ durante 30 dias prejudicaram o processo germinativo. Os demais tratamentos não apresentaram diferenças em relação ao controle.
\end{abstract}

Palavras chave: Caryocar brasiliense, pequi, germinação, cerrado.

\begin{abstract}
Effects of different treatments in the germination of pequi (Caryocar brasiliense Camb.)). Seeds of pequi (Caryocar brasiliense Camb.) collected from fallen fruits on the soil surface under the tree and those from maturing fruits still on the tree were submitted to the following treatments: humid heating $\left(80^{\circ} \mathrm{C} / 15 \mathrm{~min}\right)$, dry heating $\left(80^{\circ} \mathrm{C} / 15 \mathrm{~min}\right.$ and $50^{\circ} \mathrm{C}$ during $30,60,90$ and $120 \mathrm{~min})$, gibberellic acid $100 \mathrm{mg} / \mathrm{l}(24 \mathrm{~h})$ and 6-benzylamynopurine $10^{-4} \mathrm{M}(24 \mathrm{~h})$, concentrated sulphuric acid $(1 \mathrm{~h})$ and running tap water $(48 \mathrm{~h})$. Seeds of fruits collected from the soil surface, with part of the mesocarp removed, and those maturing fruits from the tree, with intact mesocarp, were stored at $5^{\circ} \mathrm{C}$ during 30 days, followed or not by addition of $\mathrm{GA}_{3} 100 \mathrm{mg} / \mathrm{l}$. It was observed that seed germination started consistently 9 months after sowing and that there was no significant difference
\end{abstract}

\footnotetext{
' Departamento de Botânica, ICB/UFG, 74001-970, Goiânia-GO, Brasil. Bolsista do CNPq.

${ }^{2}$ Curso de Agronomia da UFG. Bolsista de Iniciação Científica do CNPq.

${ }^{3}$ Departamento de Horticultura, EA/EFG.
} 
between germination of seed proceeding from maturing fruits $(85 \%)$ and those collected from the soil surface $(67 \%)$. Seeds treated with $80^{\circ} \mathrm{C} / 15 \mathrm{~min}$., with conc. sulphuric acid $1 \mathrm{~h}$ and stratified at $5^{\circ} \mathrm{C}$ during 30 days germinated at a smaller percentage than controls. Other treatments did not affect significantly seed germination when compared with the control.

Key words: Caryocar brasiliense, "pequi", germination, "cerrado".

\section{Introdução}

Planta perene de ocorrência em cerrados brasileiros, o pequizeiro (Caryocar brasiliense Camb.) apresenta elevado potencial econômico, podendo ser utilizado no reflorestamento e na fabricação de postos e mourões. Seu fruto, com elevado teor em vitaminas e substâncias graxas, é consumido na alimentação e utilizado no fabrico de licor e óleo comestível (Ferreira 1973, Peixoto 1973).

Embora possa ser totalmente aproveitado, pouco se sabe acerca do crescimento e desenvolvimento do pequizeiro. Heringer (1962) observou que raramente são vistas plantas novas de pequi em condições naturais, entretando, foram observadas por Labouriau et al. (1963, 1964) e Válio \& Moraes (1966) germinação de Caryocar brasiliense em condições de cerrado.

Tem sido relatado que sementes de pequi apresentam porcentagem de germinação baixa e irregular (Conceição 1984). Heringer (1962, 1970) observou que sementes de $C$. brasiliense apresentavam, após 12 meses de plantio, $45 \%$ de germinação e sugeriu a existência de um possível inibidor de crescimento no putâmen. Sementes de pequi colocadas em congelador de geladeira comum por 24 horas apresentaram porcentagens de germinação de 20 a $25 \%$ com o aparecimento das primeiras plantas entre 40 e 50 dias (Borges 1986). Miranda (1986) observou que a germinação da amêndoa de $C$. brasiliense foi superior à de semente inteira ou fendida. Silva (1989), obteve $30 \%$ de germinação 60 dias após semeadura do pequi.

A germinação de sementes é afetada tanto pela presença de tegumento duro, que impede a expansão do embrião, quanto pelo balanço endógeno entre inibidores e promotores de crescimento. A imaturidade do embrião e fatores externos como luz e temperatura também influenciam a germinação por alterar os níveis endógenos dos hormônios.

A resistência exercida pelo tegumento pode ser quebrada por vários tratamentos, como a escarificação mecânica (Rizzini 1970, Reis 1976, Felippe 1984, Klein \& Felippe 1992), e química com ácido sulfúrico concentrado (Freitas \& Candido 1972; Freitas et al. 1990); acetona (Tao \& Khan 1974), álcool (Barnett 1970), etc. A aplicação exógena de reguladores de crescimento modifica, em algumas sementes, as exigências de temperatura e induz a germinação (Reynolds \& Thompson 1973). Ácido abscísico (Figueiredo \& Ferreira 1991), ácido giberélico, citocininas e etileno (Miller 1956, Toole \& Carthy 1961, Usberti \& Felippe 1979, Cardoso \& Felippe 1983) estão relacionados, respectivamente, com inibição e promoção da germinação.

Este trabalho teve por finalidade obter informações sobre o melhor tratamento de sementes de $C$. brasiliense, espécie de pequizeiro ocorrente no Brasil Central, 
visando antecipar e uniformizar sua germinação.

\section{Material e métodos}

Foram utilizadas sementes de Caryocar brasiliense Camb. provenientes de frutos caídos no chão, completamente maduros e de frutos colhidos "de vez" (diretamente da árvore), no município de Hidrolândia - Estado de Goiás. Os frutos colhidos "de vez" foram armazenados sob condição ambiente até sua rachadura, quando as sementes foram removidas. As sementes provenientes de frutos maduros foram armazenados, nesse período, sob condição ambiente.

As sementes foram submetidas aos seguintes tratamentos: calor úmido de $80^{\circ} \mathrm{C}$ durante 15 minutos; calor seco de $80^{\circ} \mathrm{C}$ durante 15 minutos; calor seco de $50^{\circ} \mathrm{C}$ durante 30, 60, 90 e 120 minutos; ácido giberélico $\left(\mathrm{GA}_{3}\right)$ - 100mg/l durante 24 horas; 6-benzilaminopurina (BAP) $10^{-4} \mathrm{M}$ durante 24 horas; ácido sulfúrico concentrado por 1 hora; lavagem em água corrente por 48 horas e controle. Sementes provenientes de frutos coletados do chão, com parte do mesocarpo (polpa) removida com faca, e de frutos colhidos "de vez", com mesocarpo íntegro, foram armazenadas a $5^{\circ} \mathrm{C}$ durante 30 dias, seguido ou não pela adição de ácido giberélico $\left(\mathrm{GA}_{3}\right) 100 \mathrm{mg} / \mathrm{l}$ durante 24 horas. Para facilitar sua compreensão, os tratamentos efetuados estão esquematizados na Figura 1.

A condição de calor úmido foi obtida pela imersão das sementes em água com temperatura inicial de $80^{\circ} \mathrm{C}$ e, após 15 minutos, de $65^{\circ} \mathrm{C}$, e a de calor seco foi fornecida por estufa FANEM com temperatura ajustada. A estratificação foi feita colocando-se as sementes em recipientes, contendo vermiculita umedecida, envolvidos em plásticos e armazenados em refrigerador com temperatura média de $5^{\circ} \mathrm{C}$.

O tratamento com ácido sulfúrico concentrado por uma hora foi seguido pela lavagem das sementes em água corrente durante 24 horas.

A semeadura foi feita em canteiros sob condição de telado, com $50 \%$ de sombreamento, e cada tratamento constou de 6 repetições de 10 sementes.

O delineamento experimental foi o de blocos ao acaso. Os resultados obtidos foram submetidos à análise de variância e as comparações entre as médias foram feitas mediante a aplicação do teste de Tukey ao nível de 5\% de probabilidade (Gomes 1970).

\section{Resultados e discussão}

A Figura 2 mostra os dados de temperatura máxima e mínima, umidade relativa e precipitações médias mensais no local de experimentação. As sementes provenientes de frutos colhidos "de vez" e armazenados até amadurecimento completo apresentaram porcentagem de germinação de $85 \%$, enquanto que aquelas provenientes de frutos colhidos completamente maduros apresentaram $67 \%$, porém a diferença observada não foi significativa a nível de $5 \%$ de probabilidade (Figura 3). Observa-se também que as sementes, embora semeadas em janeiro, só apresentaram germinação 


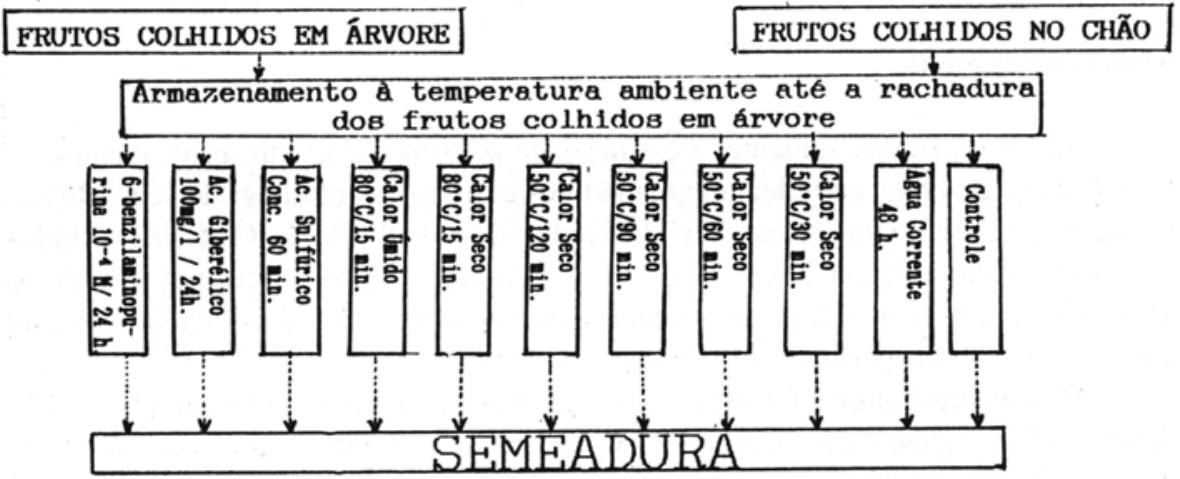

\section{SEMENTES DE FRUTOS COLHIDOS \\ EM ÁRVORE (COM MESOCARPO)}

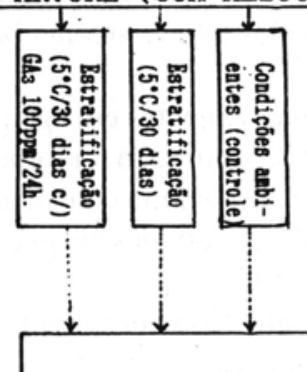

SEMENTES DE FRUTOS COLHIDOS NO CHÃO (SEM MESOCARPO)



Figura 1. Esquenıa aos tratamentus efetuados em sementes de Caryocar brasiliense Camb.

efetiva a partir do mês de outubro, nove meses após a semeadura e, em dois meses atingiram valor máximo, confirmando a ocorrência de intervalo de tempo relativamente longo entre a semeadura do pequi e sua germinação, já observada por vários autores (Heringer 1962, 1970; Miranda 1986; Borges 1986). Entretanto, a porcentagem de germinação encontrada foi superior à observada por Heringer (1962, 1970), de $45 \%$. Intervalos de tempo relativamente longos entre a semeadura e o início da germinação também foram observados em outras plantas de cerrado. Rizzini (1970) observou que em frutos de Andira humilis com endocarpo intacto a germinação só começava após período de 234 a 376 dias. Esse mesmo autor verificou também que sementes de Annona crassiflora só germinavam 200 dias após o início do experimento (Rizzini, 1973) e que, passado esse período, a germinação atingia 90\%. Rizzini (1973) sugeriu que esse comportamento talvez fosse devido à indiferenciação do embrião. Comparando a curva de germinação (Figura 3) com os dados climatológicos contidos 

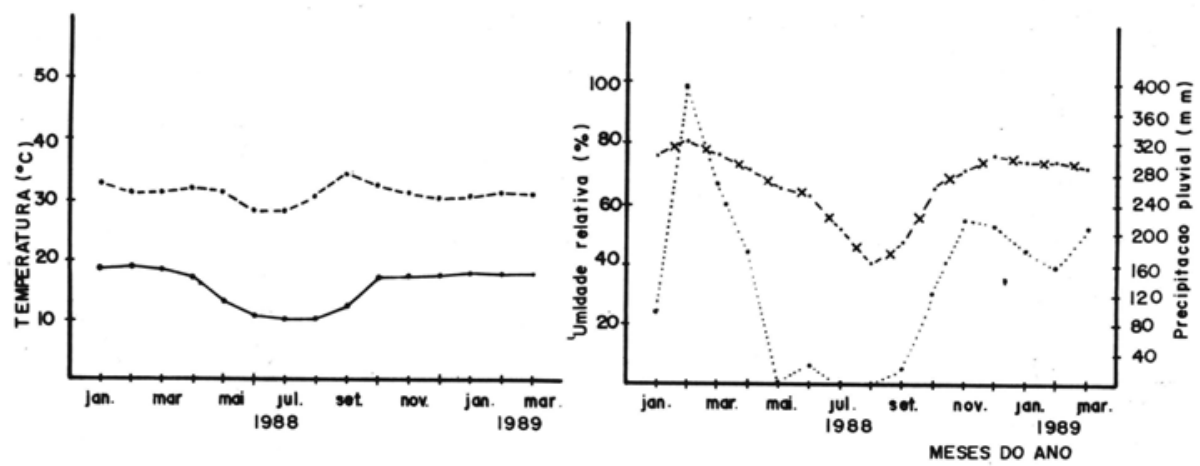

Figura 2. Variações mensais de temperaturas $\left({ }^{\circ} \mathrm{C}\right)$ máximas (----) e mínimas (- - umidade relativa (\%) (-x-X-) e precipitação pluvial (•...•) em Goiânia (GO) em 1988 e de janeiro a março de 1989.

na Figura 2, observa-se que a germinação ocorreu após período com temperaturas mínimas de $10^{\circ} \mathrm{C}$ e máximas entre 28 e $30^{\circ} \mathrm{C}$, menores umidades relativas e precipitações pluviais do ano, e coincidiu com o início das chuvas. Como foram realizadas regas diárias, o fator água parece não ser o responsável direto pelo intervalo de tempo entre a semeadura e o início da germinação. Outros fatores como a diminuição gradual de temperatura que ocorre após a semeadura (Figura 2), imaturidade do embrião ou balanço hormonal endógeno desfavorável podem estar atuando separadamente ou em conjunto na germinação de $C$. brasiliense.

A lavagem das sementes com água corrente durante 48 horas com a finalidade de remover possíveis inibidores existentes no putâmen (Heringer 1960, 1972) não influenciou o processo germinativo, como mostra a Figura 4. Esse resultado sugere que, se presentes, $\mathrm{o}(\mathrm{s})$ inibidor(es) se localizam não na polpa mas em região mais interna da semente, possivelmente próximo ao embrião e, portanto, mais difícil de ser(em) removido(s) pela lavagem em água corrente. Observa-se também que o tratamento com $\mathrm{H}_{2} \mathrm{SO}_{4}$ concentrado durante 1 hora danificou as sementes que apresentaram diminuição da porcentagem de germinação, talvez em decorrência da duração da ẹscarificação, não sendo possível detectar a impermeabilidade do tegumento como fator responsável pela demora da germinação. Foi observado por Felippe (1990) que sementes intactas de Qualea grandiflora apresentam $10 \%$ de germinação em 22 dias enquanto que quando escarificadas com ácido sulfúrico concentrado por 30 minutos a porcentagem de germinação obtida foi de $40 \%$ em 12 dias.

Na Figura 5 observa-se que o tratamento com temperatura de $5^{\circ} \mathrm{C}$ durante 30 dias diminui a porcentagem de germinação de sementes de $C$. brasiliense. As sementes coletadas do chão e que tiveram parte de sua polpa removida apresentaram maior sensibilidade a baixa temperatura que aquelas provenientes de frutos "de vez" com a polpa íntegra. Esses resultados podem ser devidos tanto ao ataque de microorganis- 


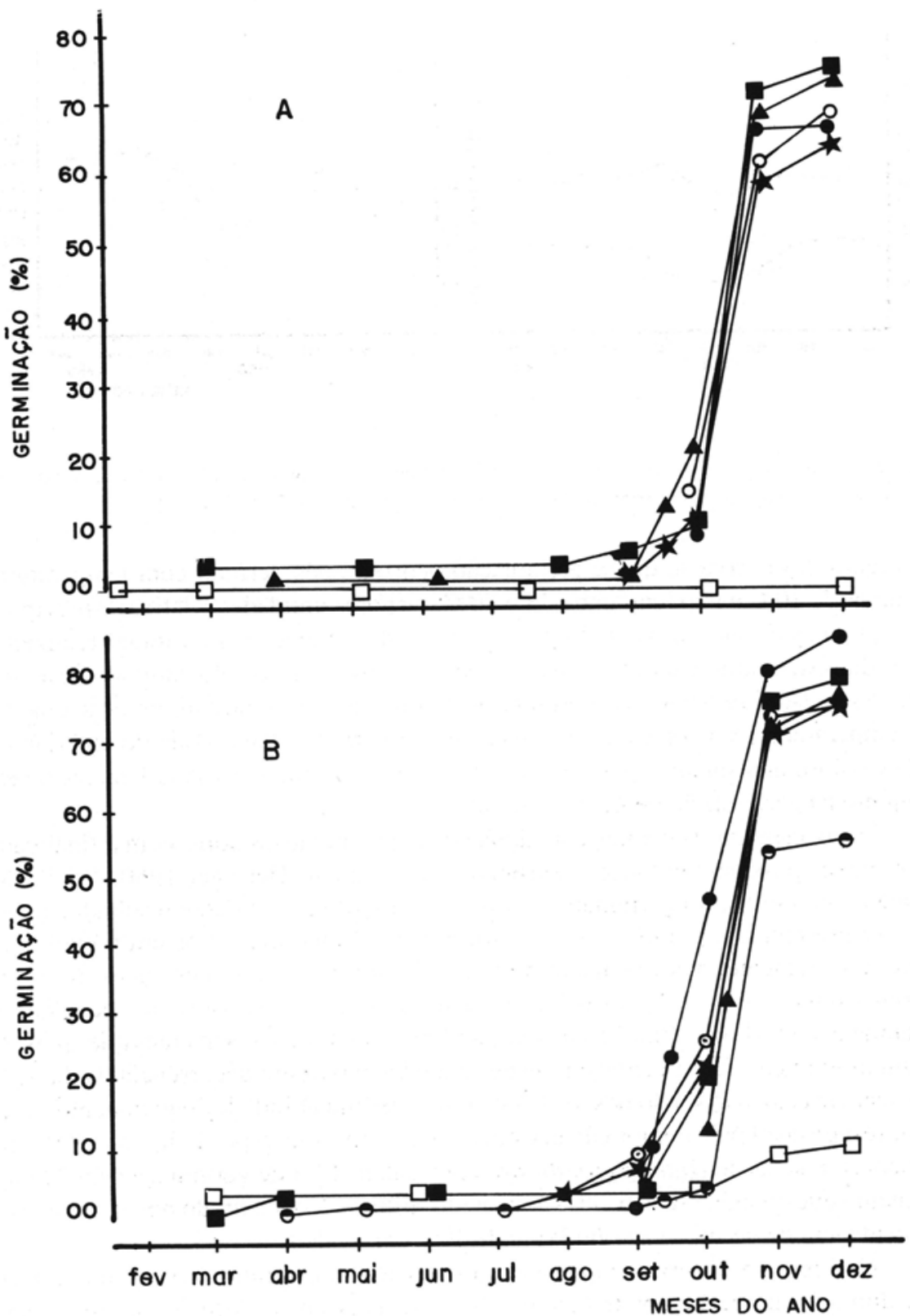

Figura 3. Efeito de tratamentos pré-plantio na germinação de sementes de C. brasiliense coletadas no chão (A) e de frutos colhidos em pré-maturação (B). Calor únido $80^{\circ} \mathrm{C} / 15 \mathrm{~min}-\square$-; calor seco $80^{\circ} \mathrm{C} / 15 \mathrm{~min}$ $\rightarrow-$ calor seco $50^{\circ} \mathrm{C} / 30 \mathrm{~min}-\mathbf{-}-; 60 \mathrm{~min}-\mathbf{\Delta}-; 90 \mathrm{~min}-\star-; 120 \mathrm{~min}-\mathrm{O}-$; testemunha - - - 

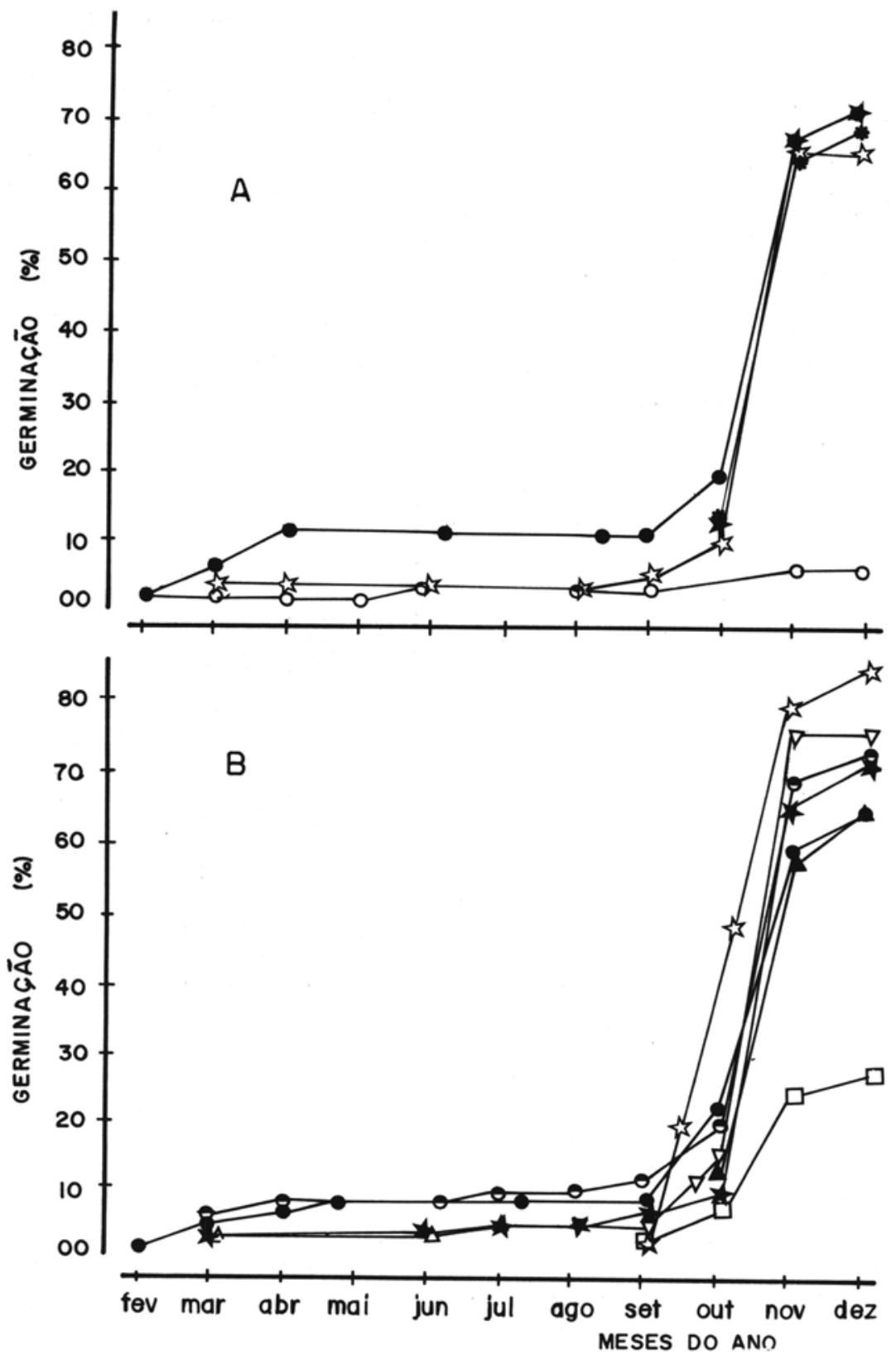

Figura 4. Efeito de tratamentos pré-plantio na germinação de sementes de C. brasiliense coletadas no chão (A) e frutos colhidos em pré-maturação (B) $\mathrm{GA}_{3} 100 \mathrm{mg} / \mathrm{l} / 24 \mathrm{~h}-\bullet-; 6 \mathrm{BPA}-10^{-4} \mathrm{M} / 24 \mathrm{~h}-\star-; \mathrm{H}_{2} \mathrm{SO}_{4} / \mathrm{l}$ hora -O-; água corrente $/ 24 \mathrm{~h}-\nabla-;$ água corrente $/ 48 \mathrm{~h}-*-; 5^{\circ} \mathrm{C} 30$ dias $+\mathrm{GA}_{3} 100 \mathrm{mg} / 124 \mathrm{~h}-\ominus-;$ remoção polpa $+50^{\circ} \mathrm{C} / 30$ dias $+\mathrm{GA}_{3} 100 \mathrm{mg} / \mathrm{l} / 24 \mathrm{~h}-\square$-; testemunha - 
mos, cuja entrada pode ter sido facilitada pela remoção da polpa, quanto pela danificação do embrião em decorrência do tempo de armazenamento a baixa temperatura. Verifica-se também que a adição de ácido giberélico na concentração de $100 \mathrm{mg} /$ 1, não foi efetiva na promoção da germinação dessas sementes (Figura 5), seja em decorrência de sua concentração e/ou de sua ineficiência em recuperar o embrião danificado pela temperatura de $5^{\circ} \mathrm{C}$ durante 30 dias. Quando o choque com baixa temperatura é fornecido em intervalo de tempo relativamente curto, parece não ter efeito deletério em sementes de pequi, uma vez que Miranda (1986) observou que a porcentagem de germinação de sementes inteiras de Caryocar sp. foi semelhante à de sementes fendilhadas, quando os dois tipos de sementes foram submetidos à temperatura de $-2^{\circ} \mathrm{C}$ por 24 horas, propiciando $30 \%$ de germinação. Assim, o efeito da estratificação, seja na remoção de inibidores e/ou aumento de promotores de cresci-
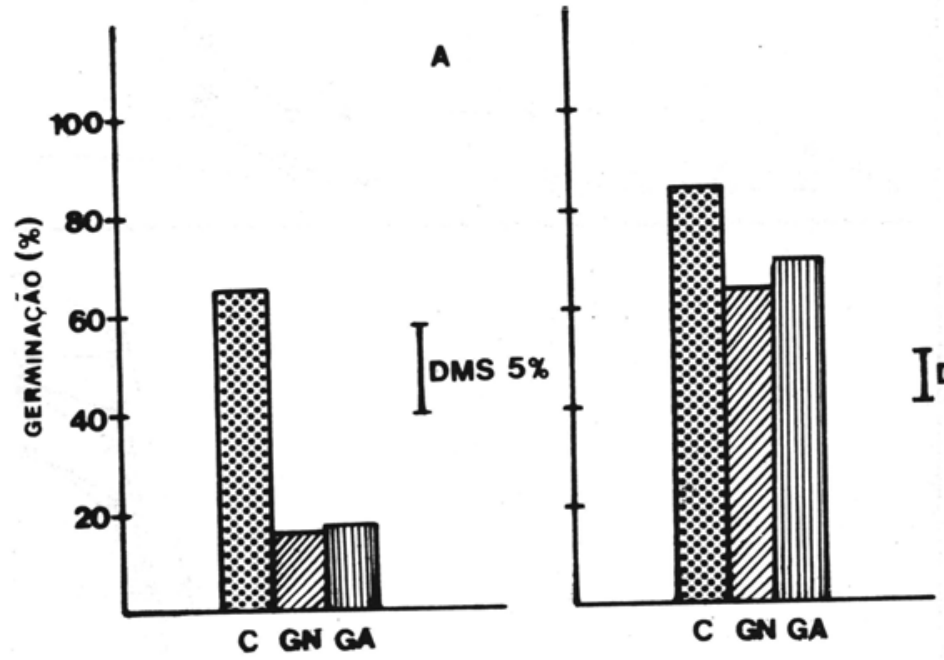

B

TRATANENTOS

Figura 5. Efeito de estratificação $\left(5^{\circ} \mathrm{C}\right)$ durante 30 dias com $(\mathrm{GN})$ e sem $(\mathrm{GA})$ posterior adição de $\mathrm{GA}_{3}(100 \mathrm{mg} / 1)$ durante 24 horas, em relação ao controle (c) na germinação de sementes de $C$. brasiliense provenientes de frutos colhidos maduros (A) e "de vez"(B)

mento com conseqüente elevação da capacidade germinativa de sementes de $C$. brasiliense, não foi observado neste trabalho.

Quando sementes de C. brasiliense foram tratadas com ácido giberélico 100 $\mathrm{mg} / \mathrm{l}$ e 6-benzilaminopurina $10^{-4} \mathrm{M}$ durante 24 horas antes da semeadura, não foram observadas diferenças significativas na porcentagem de germinação de sementes provenientes de frutos colhidos "de vez" e de frutos completamente maduros (Figura 6). Esses resultados podem ser decorrentes de concentração inadequada dos reguladores de crescimento utilizados. 


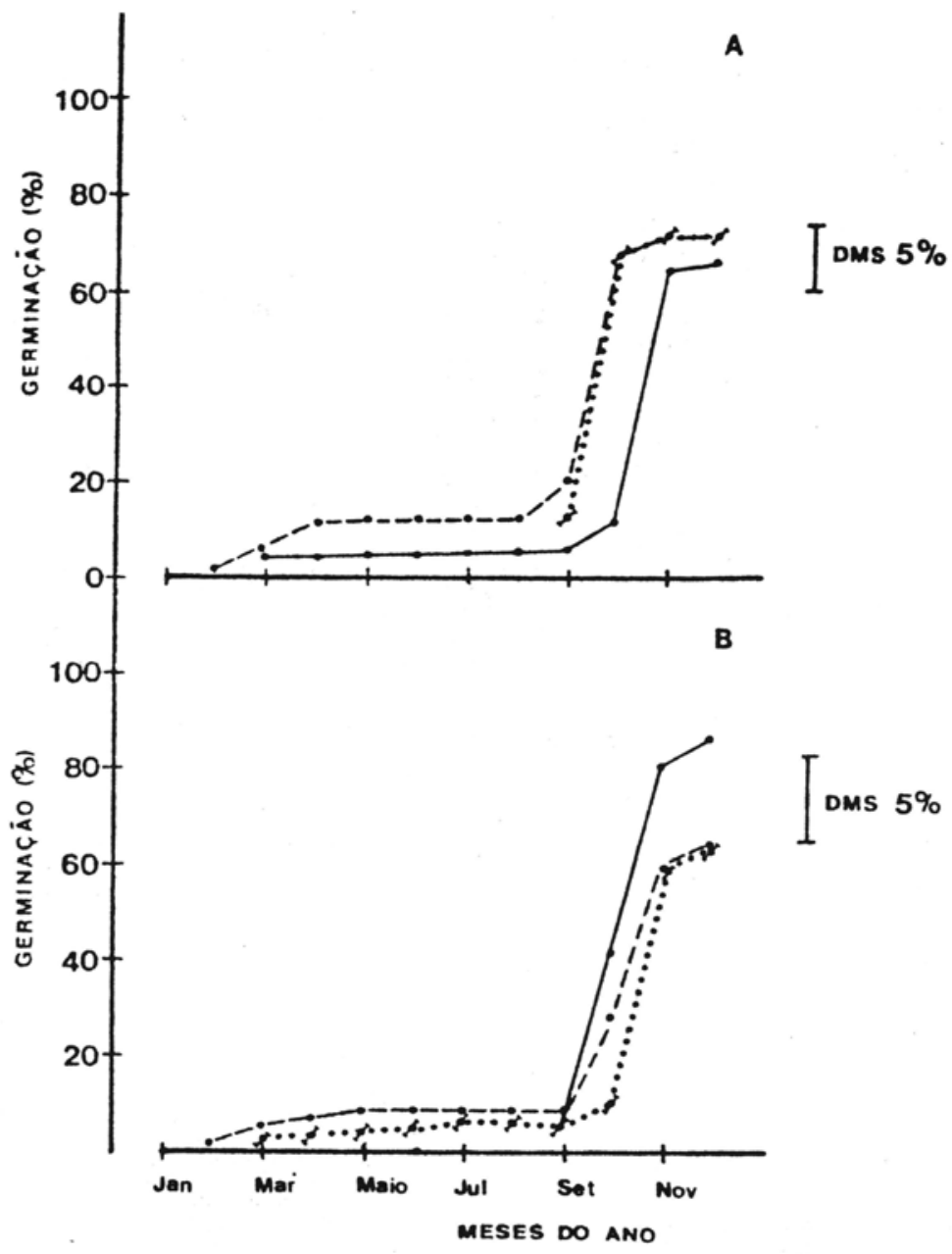

Figura 6. Efeitos de tratamentos com $\mathrm{GA}_{3}(100 \mathrm{mg} / 1)(-\cdots)$ e BAP $\left(10^{-4} \mathrm{M}\right)(\ldots)$ durante 24 horas em relação ao controle (—), na germinação de sementes provenientes de frutos colhidos maduros (A) e "de vez"(B).

O tratamento das sementes com temperatura de $80^{\circ} \mathrm{C}$, durante $15 \mathrm{~min}$, fornecida por estufa (calor seco) ou por imersão em água aquecida, diminui a porcentagem de germinação de sementes provenientes de frutos colhidos "de vez" (Figura 7) e anulou a de sementes provenientes de frutos coletados do chão (não ilustrado), sendo o calor úmido mais efetivo que o calor seco. Esses resultados parecem indicar que sementes de $C$. brasiliense são mais suscetíveis ao tratamento com temperatura elevada que as de outras espécies ocorrentes em cerrado. Rizzini (1976) observou que temperatura de $80^{\circ} \mathrm{C}$ durante $5 \mathrm{~min}$ apresentou pequena influência sobre a germinação de sementes 


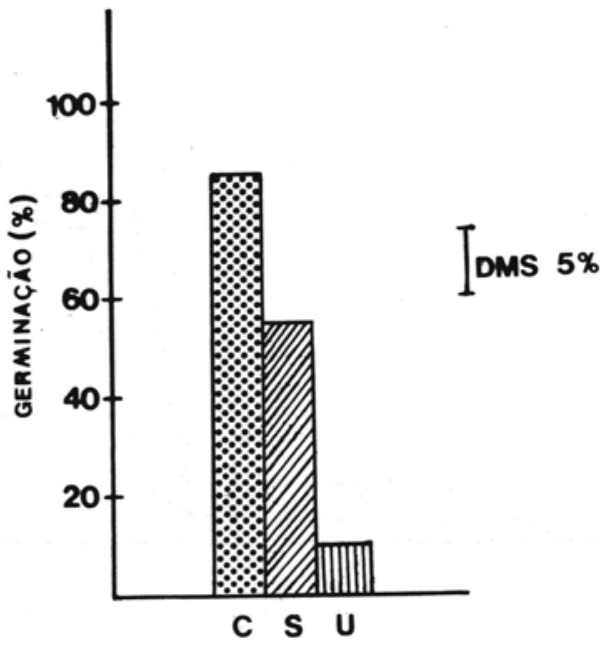

TRATAMENTOS

Figura 7. Efeitos de choques térmicos de $80^{\circ} \mathrm{C} \operatorname{seco}$ (S) e úmido (U) em relação ao controle (C) na germinação de sementes provenientes de frutos colhidos "de vez".

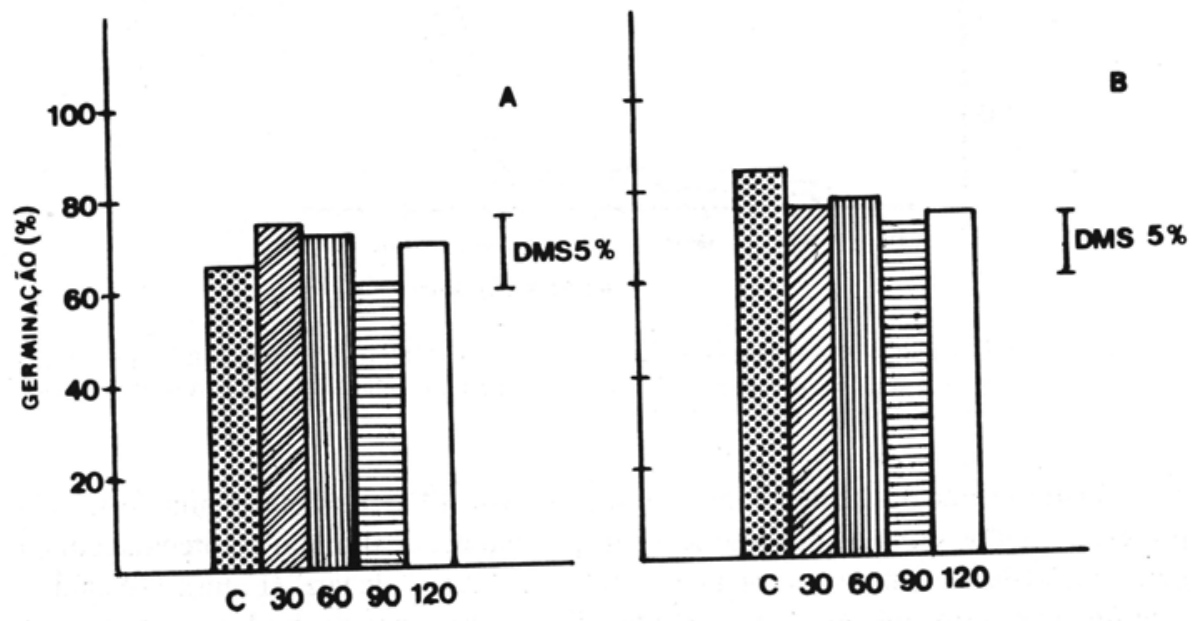

TRATAMENTOS

Figura 8. Efeito de choque térmico de $50^{\circ} \mathrm{C}$ na germinação de sementes provenientes de frutos colhidos maduros (A) e "de vez"(B). Controle (C) 30, 60, 90 e 120 minutos. 
oriundas de cerrado e que das 40 espécies savanícolas estudadas, somente Magonia pubescens e Bowdichia major demonstraram receber algum benefício quando foram submetidas a tratamento de $100^{\circ} \mathrm{C}$ por $10 \mathrm{~min}$. Sementes de Paepalanthus speciosus Koern. (Carvalho \& Ribeiro 1991), ocorrentes em campo rupestre, não são afetadas por calor seco de até $60^{\circ} \mathrm{C}$ durante $30 \mathrm{~min}$. A Figura 8 mostra que temperaturas de $50^{\circ} \mathrm{C}$, fornecidas por estufa (calor seco) durante $30,60,90$ e 120 minutos não afetaram a porcentagem de germinação de $C$. brasiliense.

\section{Agradecimentos}

Os autores agradecem à Financiadora de Estudos e Projetos (FINEP), pelo suporte financeiro. Ao Conselho Nacional de Desenvolvimento Científico e Tecnológico $(\mathrm{CNPq})$, pela concessão das bolsas de pesquisa e de iniciação científiaca. Ao Prof. Oliver J. M. Lobato, pelos dados climatológicos gentilmente fornecidos pela Estação Evaporimétrica de 1. ${ }^{a}$ Classe da Escola de Agronomia da UFG.

\section{Referências bibliográficas}

Barnett, J.P. 1970. Germination inhibitors unimportant in dormancy of southern pine seed. Forest Service USDA, SQ $112: 14$.

Borges, J.D. 1986. Semente gelada apressa o pequi. Globo Rural 5:53.

Cardoso,V.J.M. \& Felippe,G.M. 1983. Endogenous hormones and the germination of Cucumis anguria L. Revta bras. Bot. 6:29-31.

Carvalho,C.G.Sá \& Ribeiro, M.C., 1991. Germinação de Paepalanthus speciosus Koern. ocorrentes na Serra Dourada- GO. Resumos do XLII Congresso Nacional de Botânica, Goiânia, p.347.

Conceição, P.N. 1984. Reflorestamento de cerrado com a espécie Caryocar coriaceum With. Revista Agroceres 17:25-31.

Felippe, G.M. 1984. Germinação de Zornia reticulata, uma espécie dos cerrados. Anais do IV Congresso da SBSP p. 7-13.

Felippe, G.M. 1990. Qualea grandiflora the seed and its germination. Revta bras.Bot. 13:33-37.

Ferreira, M.B. 1973. Frutos comestíveis do Distrito Federal - III. O cerrado. 5(20):22-25.

Figueiredo, P.S. \& Pereira, M.F. 1991. Germinação de sementes imaturas de Phaseolus vulgaris: envolvimento do ácido abscísico. Revta bras.Bot. 14:83-88.

Freitas,J.A.C. \& Candido, J.F. 1972. Tratamento químico para abreviar germinação de sementes de guapuruvu (Schyzolobium excelsum Vog.) e mamoneira (Tachigalia multijuga Benth.) Seiva 32:1-10.

Freitas, R.R., Carvalho, D.A. \& Alvarenga, A.A. 1990. Quebra de dormência e germinação de sementes de capim-marmelada Brachiaria plantaginea (Link) Hitch. Revta bras.Bot. 2(2):31-35.

Gomes, F.P. 1970. Curso de Estatística experimental, São Paulo: Ed. Nobel S/A.

Heringer, E.P. 1962. Pequizeiro (Caryocar brasiliense Cambess) Anais do XI Congresso Nacional de Botânica. 1:113-118.

Heringer, E.P. 1970. O Pequizeiro (Caryocar brasiliense Cambess). Brasil Florestal 1:28-31.

Klein, A.L. \& Felippe, G.M. 1992. Germinação de ervas invasoras: escarificação e luz. Anais do VIII Congresso da SBSP. p.47-56.

Labouriau, L.G.; Valio, I.F.M.; Labouriau, M.L.S. \& Handro,W. 1963. Nota sobre a germinação de sementes de plantas de cerrado em condições naturais. Rev.bras.Biol. 23(3) :227-237.

Labouriau, L.G.; Válio, I.F.M. \& Heringer, E.P. 1964. Sobre o sistema reprodutivo de plantas de cerrado. I. An. Acad. bras. Ciênc. 36(4) :449-464.

Miller, C.O. 1956. Similarity of some kinetin and red light effects. Plant Physiol. 31:318-319. 
Miranda, J.S. 1986. Contribuição ao estudo da cultura do piqui (Caryocar sp.): propagação e concentração de nutrientes. Dissertação de mestrado. Areia-PB.

Peixoto, A.R. 1973. O piqui e a lavoura no cerrado. In: Plantas oleaginosas arbóreas. São Paulo: Nobel.

Reis, G.G. 1976. Estudo sobre a dormência de sementes de sucupira (Pterodon pubescens Benth). Dissertação de mestrado. Viçosa.

Reynolds, T. \& Thompson, P.A. 1973. Effects of kinetin, gibberellins and (+) -abscisic acid on the germination of lettuce (Lactuca sativa). Physiol.Plant. 28:516-522.

Rizzini, C.T. 1970. Inibidores de germinação e crescimento em Andira humilis Benth. An.Acad.brasil.Ciênc. 42(Supl.) :329-366.

Rizzini, C.T. 1973. Dormancy in seeds of Annona crassiflora Mart. J.exp.Bot. 24:117-123.

Rizzini, C.T. 1976. Influência da temperatura sobre a germinação de diásporos de cerrado. Rodriguésia 41:341-383.

Silva,J.A. 1989. Formação de mudas, um processo fácil. $O$ Popular de 22.11.89. p. 10.

Tao, K.L. \& Khan, A.A. 1974. Penetration of dry seeds with chemicals applied in acetone.Plant Physiol.54:956-958.

Toole, V.K. \& Carthy, H.M. 1961. Responses to gibberellin of light-requiring seeds of lettuce and Lepidium virginicum. Plant Physiol. 36: 663-671.

Usberti, R. \& Felippe, G.M. 1979. Storage conditions and endogenous levels of gibberellins, cytokinins, and inhibitors in seeds of Citrus limonia Osb. Revta bras.Bot.2(2):107-111.

Válio, I.F.M. \& Moraes,V. 1966. Sobre o sistema reprodutivo de plantas dos cerrados - II. An.Acad.bras. Ciênc. 38:219-228. 